\title{
Iron oxidation state in (Mg,Fe)O: calibration of the flank method (EMPA) as a new technique for diamond inclusion studies
}

\author{
M. Longo and C.A. McCammon \\ Bayerisches Geoinstitut,Universität Bayreuth, D-95440 Bayreuth, Germany
}

\section{Introduction}

The lower mantle consists predominantly of $(\mathrm{Mg}, \mathrm{Fe})(\mathrm{Si}, \mathrm{Al}) \mathrm{O}_{3}$ perovskite and $(\mathrm{Mg}, \mathrm{Fe}) \mathrm{O}$ ferropericlase. Studying these phases is therefore critical to determining redox conditions and their consequences for mantle properties and dynamics. Studies have shown that the $\mathrm{Fe}^{3+}$ concentration in $(\mathrm{Mg}, \mathrm{Fe})(\mathrm{Si}, \mathrm{Al}) \mathrm{O}_{3}$ perovskite is essentially insensitive to oxygen fugacity; hence our attention is turned to ( $\mathrm{Mg}, \mathrm{Fe}) \mathrm{O}$. Our goal is to calibrate the "flank method" by electron microprobe using synthetic $(\mathrm{Mg}, \mathrm{Fe}) \mathrm{O}$, and then apply the method to determine in situ $\mathrm{Fe}^{3+} / \Sigma \mathrm{Fe}$ in ferropericlase inclusions from lower mantle diamonds. Up until now a calibration of the flank method has been reported only for garnets (Höfer and Brey, 2007).

\section{Sample synthesis and experimental methods}

The calibration sample suite consists of synthetic $(\mathrm{Mg}, \mathrm{Fe}) \mathrm{O}$ crystals covering a wide range of composition $\left(\mathrm{x}_{\mathrm{Fe}}=2\right.$ to 70 at. $\%$ ) and $\mathrm{Fe}^{3+} / \Sigma \mathrm{Fe}$ (1 to $14 \%$ ). To synthesize the samples, $\mathrm{Mg}$ and Fe metals were mixed in stoichiometric proportions to give a compositional range of $2-60$ at $\% \mathrm{Fe}$ in $(\mathrm{Mg}, \mathrm{Fe}) \mathrm{O}$. Metals were first dissolved in $\mathrm{HNO}_{3}$, and then the mixture was heated to $50^{\circ} \mathrm{C}$ to allow $\mathrm{HNO}_{3}$ to slowly evaporate. Subsequently $\mathrm{NO}_{3}$ was added to obtain oxide precipitates. Excess $\mathrm{HNO}_{3}$ and $\mathrm{NO}_{3}$ were then removed by drying the obtained gels using a Bunsen burner $\left(1200-1500^{\circ} \mathrm{C}\right)$. All synthetic powders were then equilibrated in a gas-mixing furnace under $\mathrm{CO} / \mathrm{CO}_{2}$ at $1300^{\circ} \mathrm{C}$ and controlled oxygen fugacity in order to obtain a wide range of $\mathrm{Fe}^{3+} / \Sigma \mathrm{Fe}$. Oxygen fugacities were varied over the range $10^{-7}$ to $10^{-11}$ and were monitored during the experiments using an oxygen fugacity sensor. X-ray powder diffraction and Mössbauer spectroscopy were used to verify the structure of the polycrystalline powders and to determine $\mathrm{Fe}^{3+} / \Sigma \mathrm{Fe}$. The range of $\mathrm{Fe}^{3+} / \Sigma \mathrm{Fe}$ obtained was between 1 and 15 at $\%$.

In order to obtain the high quality surfaces needed for electron microprobe measurements, the polycrystalline samples were transformed to quasi single crystals at high pressure and temperature using a multianvil apparatus. The $(\mathrm{Mg}, \mathrm{Fe}) \mathrm{O}$ polycrystalline powders were loaded into $\mathrm{Re}$ capsules of $1.6 \mathrm{~mm}$ diameter and $2 \mathrm{~mm}$ long. Samples were compressed to $15 \mathrm{GPa}$ and heated to $1800-2000^{\circ} \mathrm{C}$ for about one hour.

Crystals were analyzed using point-source Mössbauer spectroscopy to determine the final $\mathrm{Fe}^{3+} / \Sigma \mathrm{Fe}$ and then were mounted in epoxy for study using the electron microprobe. Quantitative plus qualitative analysis were performed at $15 \mathrm{kV}$ and $80 \mathrm{nA}$ according to the procedure developed for garnets by Höfer and Brey (2007). Measurements were performed using a beam size of $1 \mu \mathrm{m}$. Each $\mathrm{L} \beta$ and $\mathrm{L} \alpha$ position was counted for $300 \mathrm{~s}$ at each selected point. Spectrometer drifts which may occur during the measurements were monitored by analyzing one of the synthetic $(\mathrm{Mg}, \mathrm{Fe}) \mathrm{O}$ samples at the start and finish of each session. The reproducibility of flank method measurements was also investigated by monitoring $\mathrm{L} \beta / \mathrm{L} \alpha$ ratios over several microprobe sessions. Data comparison shows that $\mathrm{L} \beta / \mathrm{L} \alpha$ ratios collected on different days are slightly different, but fall within experimental error (Fig.1).

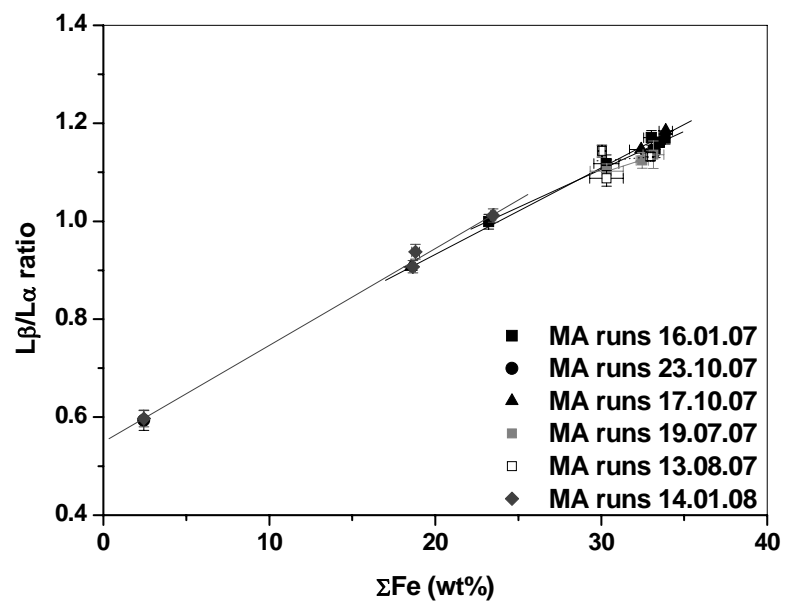

Fig. 1 - Reproducibility of flank method measurements on different days (date indicated) for the same set of (Fe, Mg)O crystals. No significant change in slope is apparent for different electron microprobe measuring days.

\section{Results and discussion}

We observe a positive correlation between $\Sigma \mathrm{Fe}$ and $\mathrm{L} \beta / \mathrm{L} \alpha$ in accordance with the work on garnets by Höfer and Brey (2007) (Fig.2), and also a positive correlation of $\mathrm{L} \beta / \mathrm{L} \alpha$ ratios with $\mathrm{Fe}^{2+}$ (Fig.3). However 
in contrast with the garnet results, the two correlations for $(\mathrm{Mg}, \mathrm{Fe}) \mathrm{O}$ are distinctly nonlinear. This likely arises from the nonlinear variation of weight fraction across the ferropericlase solid solution compared to garnet, where the smaller variation in the latter gives a near linear trend (Fig.4).

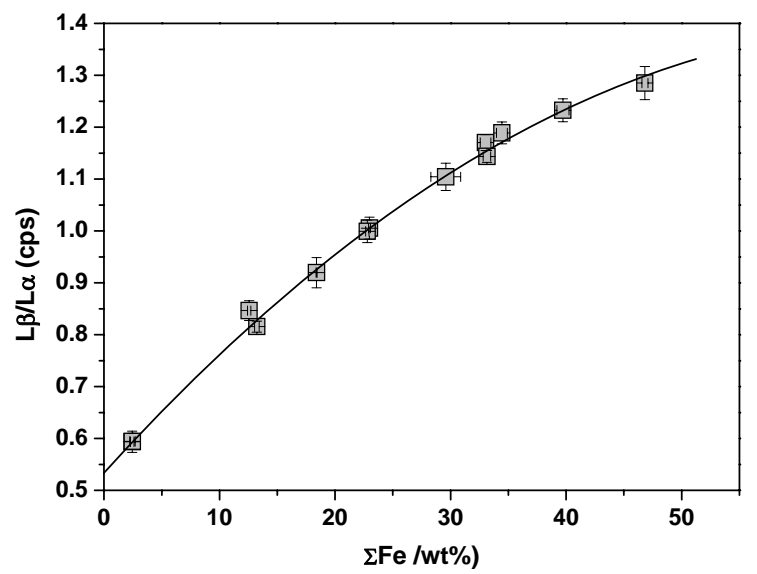

Fig. $2-\mathrm{L} \beta / \mathrm{L} \alpha$ variation as a function of $\Sigma \mathrm{Fe}(\mathrm{wt} \%)$ for $(\mathrm{Mg}, \mathrm{Fe}) \mathrm{O}$ crystals.

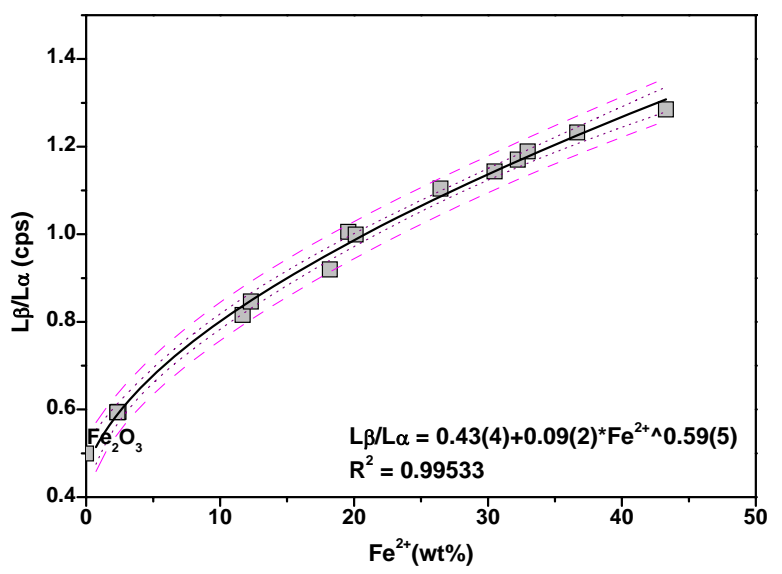

Fig. $3-\mathrm{L} \beta / \mathrm{L} \alpha$ variation as a function of $\mathrm{Fe}^{2+}(\mathrm{wt} \%)$ for $(\mathrm{Mg}, \mathrm{Fe}) \mathrm{O}$ crystals calculated from Mössbauer data. Dashed and dotted lines indicate the $95 \%$ confidence and prediction intervals, respectively.

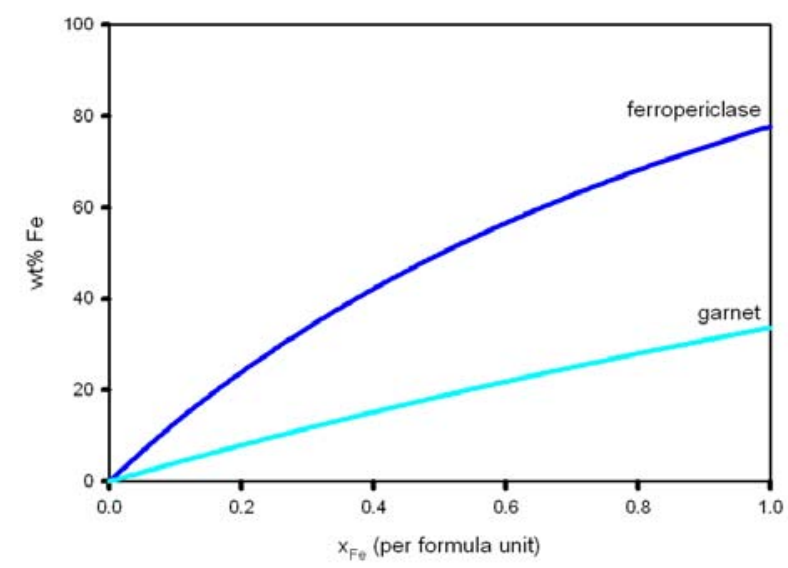

Fig. 4 - Variation of $w t \% F e$ as a function of Fe molar fraction for ferropericlase and garnet (pyrope-almandine) solid solutions.
Following the approach of Höfer and Brey (2007), we applied a least-squares regression model to fit the three variables $\Sigma \mathrm{Fe}, \mathrm{L} \beta / \mathrm{L} \alpha$ and $\mathrm{Fe}^{2+}$, and looked for the simplest equation that was able to fit the data. Thus, for $(\mathrm{Mg}, \mathrm{Fe}) \mathrm{O}$ with $\mathrm{x}_{\mathrm{Fe}}$ between 2 and $36.6 \mathrm{wt} \%$ we report the following calibration:

$$
\begin{aligned}
\mathrm{Fe}^{2+}= & 46.238+8.161 * \ln (\Sigma \mathrm{Fe})-137.01 *(\mathrm{~L} \beta / \mathrm{L} \alpha)+ \\
& +85.57 *(\mathrm{~L} \beta / \mathrm{L} \alpha)^{2} \\
\mathrm{R}^{2}= & 0.9967
\end{aligned}
$$

where $\mathrm{Fe}^{2+}$ and $\Sigma \mathrm{Fe}$ are in wt $\%$. A comparison between $\mathrm{Fe}^{3+} / \Sigma \mathrm{Fe}$ determined using flank method data and equation (1) vs. $\mathrm{Fe}^{3+} / \Sigma \mathrm{Fe}$ calculated using Mössbauer spectroscopy shows good agreement within experimental error (Fig .5).

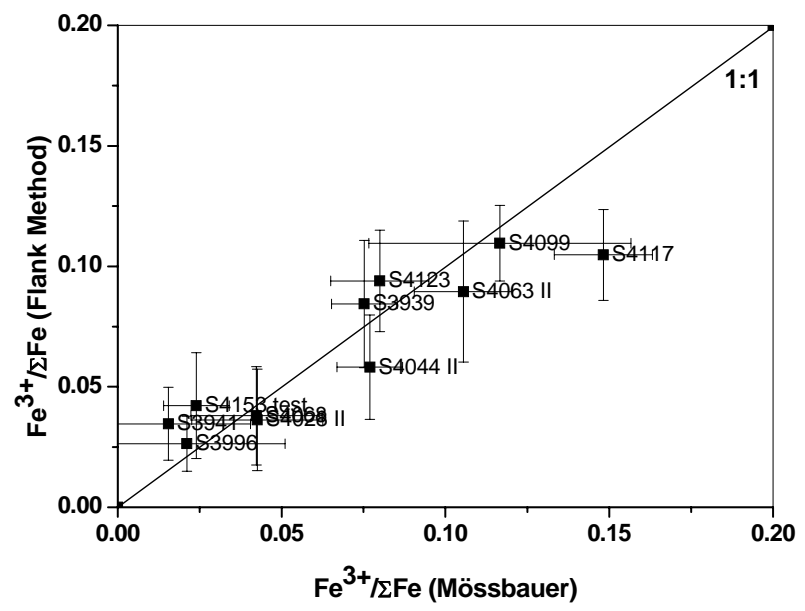

Fig. $5-\mathrm{Fe}^{3+} / \Sigma \mathrm{Fe}$ determined using the flank method according to equation (1) vs. $\mathrm{Fe}^{3+} / \Sigma \mathrm{Fe}$ determined using Mössbauer spectroscopy. The calibration was made from 11 of the synthetic $(\mathrm{Mg}, \mathrm{Fe}) \mathrm{O}$ crystals from this study.

Flank method measurements show an agreement within $1 \sigma$ which is comparable to the accuracy obtained from Mössbauer spectroscopy, but with the additional advantage of a spatial resolution on the order of $10 \mu \mathrm{m}$ (compared to no smaller than $100 \mu \mathrm{m}$ for Mössbauer spectroscopy). The flank method therefore appears to be a promising technique for determining $\mathrm{Fe}^{3+} / \Sigma \mathrm{Fe}$ in ferropericlase samples with low to moderate $\mathrm{Fe}$ concentrations.

Nearly all of the synthetic $(\mathrm{Mg}, \mathrm{Fe}) \mathrm{O}$ crystals appeared to be homogeneous as shown by the random variation of $\mathrm{L} \beta / \mathrm{L} \alpha v s$. wt $\% \mathrm{Fe}$ within the experimental error of the measurements. However sample S4149 showed a large variation in $\mathrm{wt} \% \mathrm{FeO}$ in measurements taken over different parts of the sample that was strongly correlated with $\mathrm{L} \beta / \mathrm{L} \alpha$ (Fig. 6), likely indicating that the sample was inhomogeneous. We therefore omitted sample S4149 from the calibration fitting procedure. However the results raise the possibility of quantifying inhomogeneity as a variation of $\mathrm{Fe}^{3+} / \Sigma \mathrm{Fe}$ with position in the sample, with potential application to studying dynamic processes in ferropericlase such as diffusion. 


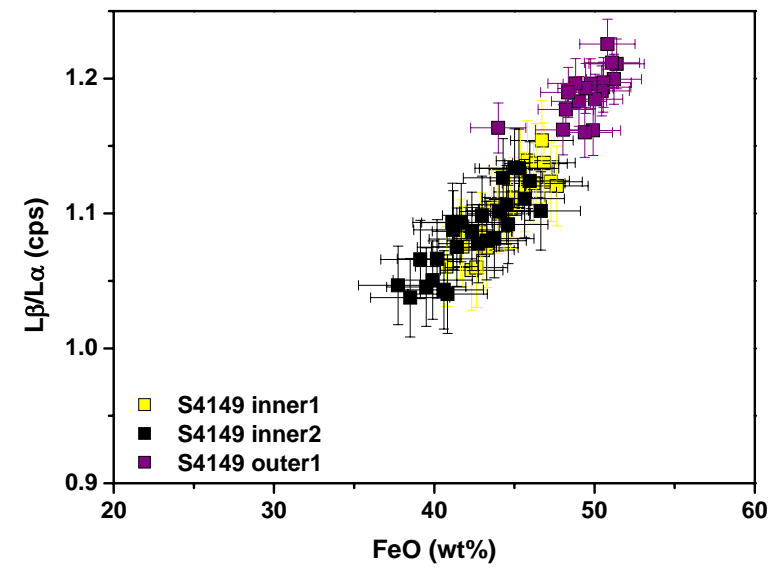

Fig. 6 - L $\beta / \mathrm{L} \alpha$ variation as a function of $\mathrm{wt} \% \mathrm{FeO}$ for sample S4149. The positive correlation observed from the inner to the outer part of the crystal indicates inhomogeneity and perhaps the effect of diffusion processes occurring during synthesis.

\section{Application to synthetic crystals containing exsolved magnesioferrite and to diamond inclusions}

We measured a second set of synthetic $(\mathrm{Mg}, \mathrm{Fe}) \mathrm{O}$ single crystals that had been synthesized by interdiffusion of $\mathrm{Fe}$ and $\mathrm{Mg}$ between single-crystal $\mathrm{MgO}$ and $(\mathrm{Mg}, \mathrm{Fe}) \mathrm{O}$ prereacted powders (Jacobsen at al., 2002). Mössbauer spectroscopy was used in this previous study to determine $\mathrm{Fe}^{3+} / \Sigma \mathrm{Fe}$, and had detected the presence of $\mathrm{Fe}(\mathrm{Mg}, \mathrm{Fe})_{2} \mathrm{O}_{4}(0.2-11$ vol.\%) which was also confirmed by TEM analysis. Our preliminary flank method data show a deviation of $L \beta / L \alpha$ from the calibration trend line (Fig. 7a), which likely results from the ferrite contribution. Thus we have a possibility to quantify the effect of $\mathrm{Fe}(\mathrm{Mg}, \mathrm{Fe})_{2} \mathrm{O}_{4}$ on $\mathrm{L} \beta / \mathrm{L} \alpha$.

We also measured a suite of four ferropericlase inclusions in lower mantle diamonds from Juina, Brazil kindly supplied by F. Kaminsky. Preliminary results from the flank method show that $\mathrm{L} \beta / \mathrm{L} \alpha$ ratios are consistent with the trend line with $\Sigma \mathrm{Fe}$ from synthetic (Mg,Fe)O crystals (Fig. 7b), suggesting a minimal contribution from magnesioferrite, and further analysis is underway to determine $\mathrm{Fe}^{3+} / \Sigma \mathrm{Fe}$ for the inclusions.

\section{Conclusions and outlook}

We used the approach of Höfer and Brey (2007) to calibrate the determination of $\mathrm{Fe}^{3+} / \Sigma \mathrm{Fe}$ using the flank method for $(\mathrm{Mg}, \mathrm{Fe}) \mathrm{O}$ with 2 to $37 \mathrm{wt} \%$ Fe. Results from measurements on inhomogeneous samples raise the possibility to quantify the variation of $\mathrm{Fe}^{3+} / \Sigma \mathrm{Fe}$ with position in samples subject to dynamic processes such as diffusion. Preliminary results on samples containing an exsolved magnesioferrite phase indicate the possibility to quantify the effect of ferrite on $L \beta / L \alpha$, with potential application to ferropericlase diamond inclusions where a ferrite phase may be present. Future work will focus on determination of $\mathrm{Fe}^{3+} / \Sigma \mathrm{Fe}$ in these natural samples, which will provide clues to redox conditions at the time of their formation.
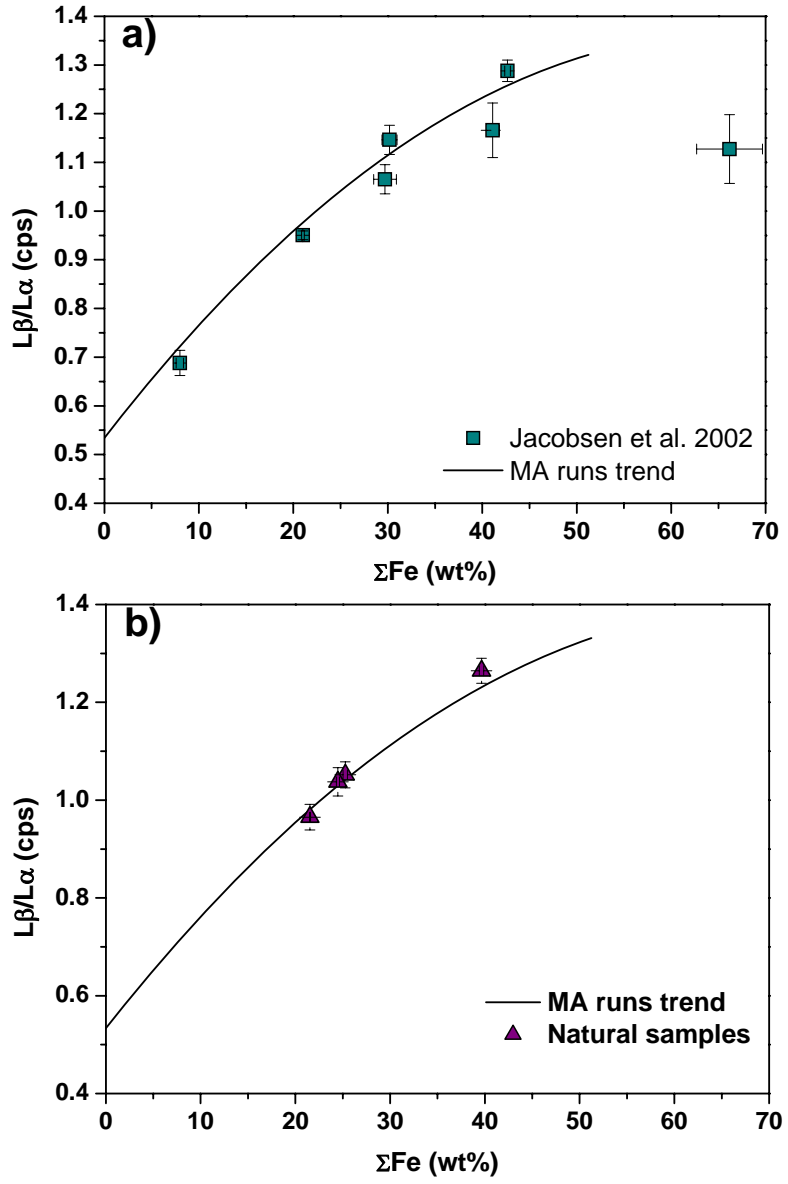

Fig. $7-\mathrm{L} \beta / \mathrm{L} \alpha$ variation as a function of $\Sigma \mathrm{Fe}(\mathrm{wt} \%)$ for synthetic single crystals from Jacobsen at al. (2002) (a) and a suite of ferropericlase inclusions from lower mantle diamonds from Juina, Brazil (b).

\section{Acknowledgments}

We are grateful to Felix Kaminsky and Steven Jacobsen for supplying some of the samples examined in this study, and to Hugh O'Neill for valuable advice concerning $(\mathrm{Mg}, \mathrm{Fe}) \mathrm{O}$ synthesis. ML received financial support from the European Commission under the Marie Curie Action for Early Stage Training of Researchers within the 6th Framework Programme (contract number MEST-CT-2005-019700).

\section{References}

Höfer, H.E. and Brey, G.P., 2007. The iron oxidation state of garnet by electron microprobe: its determination with the flank method combined with majorelements analysis. American Mineralogist, 92, 873885.

Jacobsen, S.D., Reichmann, H.-J., Spetzler, H.-A., Mackwell, S.J., Smyth, J.R., Angel, R.J. and McCammon, C.A., 2002. Structure and elasticity of single-crystal $(\mathrm{Mg}, \mathrm{Fe}) \mathrm{O}$ and a new method of generating shear waves for gigahertz ultrasonic interferometry. Journal of Geophysical Research, 107, B2, 4, 1-14. 